\title{
Redução da idade penal, tecnologias de informação e maturidade: questões à psicologia
}

\author{
Aline Kelly da Silva' \\ Simone Maria Hüning \\ Universidade Federal de Alagoas, Arapiraca - AL - Brasil
}

\begin{abstract}
Resumo: Nesse artigo, discutimos como as propostas de redução da idade penal no Brasil relacionam a expansão das tecnologias de informação e dos meios de comunicação de massa a uma mudança de maturidade dos jovens. A partir da arqueologia proposta por Michel Foucault, analisamos as Propostas de Emenda Constitucional apresentadas pela Câmara de Deputados entre os anos de 1993 e 2013. Os discursos produzidos por esses materiais atrelam meios de comunicação e tecnologias de informação com um amadurecimento psíquico precoce dos jovens e um maior grau de discernimento. Assim, propõem um deslocamento do critério cronológico de imputabilidade para a avaliação técnica da maturidade, convocando especialistas a subsidiarem decisões judiciais. Concluímos que, a partir dos efeitos de processos sociais, como o acesso à informação, os documentos propõem mais individualização das formas de punição sobre os jovens, implicando em embates políticos e éticos sobre a atuação da Psicologia nesse contexto.
\end{abstract}

Palavras-chave: maioridade penal; desenvolvimento; juventude; arqueologia; genealogia.

\section{ON THE RELATIONS BETWEEN INFORMATION, MATURITY, AND REDUCTION OF THE AGE OF CRIMINAL RESPONSIBILITY IN BRAZIL}

\begin{abstract}
This paper discusses how the proposals to reduce the age of criminal responsibility in Brazil link the expansion of information technologies and the mass media to a change in maturity of young people. Applying the archaeological method of Michel Foucault we analyze the constitutional amendment proposals presented by the country's Chamber of Deputies between 1993 and 2013. The discourses produced by these materials associate the media and information technologies with an early psychic maturation of young people and a greater degree of judgment. Thus, they propose a shift of chronological criteria for accountability in the technical evaluation of maturity, summoning experts to support judgments. We arrive at the conclusion that from the effects of social processes, such as access to information, the documents propose more individualization of forms of punishment on young people, implying political and ethical conflicts about the role of psychology in this context.
\end{abstract}

Keywords: age of criminal responsibility; development; youth; archaeology; genealogy.

SOBRE LAS RELACIONES ENTRE INFORMACIÓN, MADUREZ Y REDUCCIÓN DE LA EDAD PENAL EN BRASIL

Resumen: En este artículo discutimos cómo las propuestas de reducción de la edad penal en Brasil relacionan la expansión de las tecnologías de la información y de los

1 Endereço para correspondência: Aline Kelly da Silva, Universidade Federal de Alagoas, Instituto de Psicologia, Avenida Lourival Melo Mota, s/n, Tabuleiro dos Martins, Maceió - Alagoas - AL - Brasil. CEP: 57.072-970. E-mail: aline.silva@ip.ufal.br. 
medios de comunicación con un cambio de madurez de los jóvenes. A partir de la arqueología propuesta por Michel Foucault analizamos las Propuestas de Enmienda a la Constitución presentadas por la Cámara de Diputados entre los años 1993 y 20I3. Los discursos producidos por estos materiales vinculan medios de comunicación y tecnologías de la información a una maduración psíquica precoz de los jóvenes y un mayor grado de discernimiento. Por lo tanto, proponen un desplazamiento del criterio cronológico de imputabilidad para la evaluación técnica de la madurez, convocando a expertos para subsidiar juicios. Llegamos a la conclusión de que a partir de los efectos de los procesos sociales, como el acceso a la información, los documentos proponen más individualización de las formas de castigo hacia los jóvenes, implicando embates políticos y éticos sobre la actuación de la Psicología en este contexto.

Palabras clave: mayoría de edad penal ; desarrollo; juventud; arqueología; genealogía.

\section{Introdução}

O objetivo deste artigo é analisar o modo como as propostas de redução da idade penal relacionam a expansão das tecnologias de informação e dos meios de comunicação de massa a uma mudança de mentalidade na juventude. Ao produzirem determinados regimes de verdade, que atrelam acesso à informação com uma suposta maturidade psíquica dos jovens, essas propostas interrogam o campo da Psicologia, no tocante à produção de saberes sobre maturidade e discernimento, por exemplo, e à realização de avaliações psicológicas no contexto judicial, como discutiremos mais adiante. Desde a promulgação da Constituição Federal da República Brasileira de 1988, que fixa a idade de imputabilidade penal aos dezoito anos, a temática da diminuição da idade penal passou a ser alvo de discussão no Congresso Nacional e, posteriormente, de estudos em campos de saber tais como Psicologia, Direito, Ciências Sociais, Psiquiatria etc. A seguir, abordamos brevemente dois desses estudos (Cunha, Ropelato, \& Alves, 2006; Alves, Pedroza, Pinho, Presotti, \& Silva, 2009), que trazem questões pertinentes ao que discutiremos neste trabalho no que tange aos jogos de verdades acerca dos critérios a serem adotados para atestar a capacidade de os sujeitos serem considerados imputáveis penalmente.

Cunha, Ropelato e Alves (2006) discutiram, a partir de uma perspectiva psicológi$\mathrm{ca}$, argumentos favoráveis e contrários à redução da idade penal e analisaram a correlação entre a gravidade do ato infracional e a idade do autor quando o cometeu. Os autores consultaram 1.025 prontuários, sendo 669 de adolescentes internos no Educandário São Francisco (PR) e 356 de adultos infratores internados na Casa de Custódia de Curitiba. As idades desses dois grupos variaram de 13 a 62 anos. Os resultados obtidos apontaram, conforme os autores, que a idade é um fator que varia positivamente em relação à gravidade do delito, ou seja, quanto maior a idade, mais grave o delito.

Alves et al. (2009) debateram os argumentos a favor e contra a redução. Os autores - todos psicólogos, sendo o último também advogado - assinalaram como principal argumento favorável às propostas a consciência do autor de ato infracional ao cometê-lo e como um dos argumentos contrários a ineficácia das atuais políticas públicas, sobretudo do sistema socioeducativo. Segundo os autores, não seria adequado esta- 
belecer um marco cronológico para que os sujeitos possam ter pleno conhecimento de suas ações, uma vez que, ao considerar somente marcadores biológicos, deixam-se de lado os fatores culturais e educacionais, por exemplo.

Os debates em torno da faixa etária e da consciência dos sujeitos trazem, a nosso ver, uma discussão cara à Psicologia, ao colocar as seguintes questões: a partir de quais critérios pode-se demarcar um amadurecimento intelectual e afetivo-emocional dos sujeitos? A faixa etária é um fator satisfatório para se ponderar essa questão? Ou seria necessário considerar os processos psicossociais e os contextos nos quais se produzem as subjetividades? Nesse caso, quais os efeitos de se levar em conta esses processos psicossociais?

A relevância que esse debate possui para o campo de conhecimento e atuação da Psicologia fica explicitada nos posicionamentos adotados pelo Conselho Federal e associações da profissão (Conselho Federal de Psicologia, 2007, 2013a). Em uma das notícias publicadas no site do Conselho Federal de Psicologia (CFP), informa-se que as dezoito entidades que compõem o Fórum de Entidades da Psicologia Brasileira, o FENPB, passaram a se mobilizar contra a redução da idade penal no país, lançando a campanha "Entidades da Psicologia em campanha contra a redução da maioridade penal!" (Conselho Federal de Psicologia, 2007). Além disso, houve a publicação do documento "Redução da idade penal: socioeducação não se faz com prisão" (Conselho Federal de Psicologia, 2013b), em que o CFP posiciona-se contrariamente à redução da idade penal. Nesse trabalho, discutiremos o modo como as referidas propostas relacionam à expansão das tecnologias de informação e dos meios de comunicação de massa a uma mudança de mentalidade na juventude e, a partir disso, propõem uma substituição de um critério cronológico para um critério psicossocial ou "subjetivo-psicológico" nas decisões judiciais acerca da imputabilidade/inimputabilidade de jovens autores de atos infracionais. Tais tecnologias de informação constituem-se como um importante vetor de produção de subjetividades que torna possíveis certas formas de governar os jovens.

Adotamos o conceito de juventude (e não de adolescência) por concordarmos com Coimbra, Bocco e Nascimento (2005) sobre a vinculação do conceito de adolescência a perspectivas psicológicas que naturalizam certas características como sendo intrínsecas a uma determinada etapa da vida. Ainda que o conceito de juventude também esteja relacionado à delimitação de uma faixa etária - o que adquire importância especialmente no contexto de formulação de políticas públicas para um determinado segmento populacional - uma especificidade dele está em considerar os modos de ser dos sujeitos como múltiplos, sendo mais pertinente falar em juventudes e culturas juvenis e levar em consideração as singularidades e a potência da vida desses sujeitos em suas múltiplas vivências (Bocco, 2006; Novaes, Cara, Silva, \& Papa, 2006). Ao operarmos com o conceito de juventude, consideramos que não há um desenvolvimento universal nem um ideal de maturidade a ser atingido, pois as subjetividades são efeitos de processos socioculturais e discursos que atravessam e produzem os sujeitos. 


\section{Método}

Materiais de análise: Tomamos como materiais de análise as Propostas de Emenda à Constituição apresentadas pelos deputados brasileiros no Congresso Nacional, no período de 1993 a 2013. Uma Proposta de Emenda Constitucional (PEC) é, como o próprio nome sugere, uma emenda que altera a Constituição Federal. De acordo com Santana (1993), as emendas à Constituição possuem um alcance mais restrito do que as revisões, apresentando modificações parciais, pontuais ou fragmentárias de um texto constitucional. Um detalhe significativo é que as emendas não se inserem no texto constitucional, mas registram-se ao lado ou abaixo da redação original do texto constitucional que passa a ser modificado.

Na Câmara dos Deputados, uma PEC passa primeiramente pela Comissão de Constituição e Justiça e de Cidadania (CCJC). Se houver admissibilidade, ela é enviada à Comissão Especial para análise de conteúdo. Caso haja admissibilidade, nomeia-se um relator e envia-se a proposta para votação no Plenário da Câmara. A estrutura de uma PEC geralmente é composta de: número da PEC, identificação do artigo original a ser alterado, redação da emenda proposta para o artigo, texto de justificação que fundamenta a alteração proposta, nomes e assinaturas dos proponentes e, por fim, assinaturas dos legisladores favoráveis à proposição. $A$ análise empreendida para este trabaIho voltou-se aos textos de justificação das PECs.

Apesar de a primeira PEC que propõe diminuição da idade penal ser a PEC 14/1989, de autoria do então deputado Telmo Kirst (PDS-RS), ela foi arquivada. Desde 1993 até o período de nossa última busca em 2013, 37 PECs propunham alteração da idade penal somente na Câmara de Deputados, além das propostas apresentadas pelo Senado Federal. Nessa pesquisa, escolhemos utilizar somente os documentos produzidos na Câmara. Acessamos os textos completos de todas as propostas pelo site da Câmara dos Deputados, alguns contidos nos Diários da Câmara dos Deputados e outros de modo avulso. Das 37 propostas, sete delas não estavam disponibilizadas on-line. Entramos em contato com o serviço Fale Conosco, por meio do próprio site, e, após o recebimento via e-mail das demais propostas, chegamos ao total de 37 documentos.

Procedimentos de análise: As teorizações de Michel Foucault nortearam a produção e a análise dos dados. Adotamos a arqueologia foucaultiana como método de pesquisa que se ocupa da episteme dos saberes, ou seja, volta-se à análise de suas condições históricas de possibilidade e preocupa-se em analisar as camadas discursivas e as relações colocadas em funcionamento por determinados enunciados (Foucault, 1969/2012). Ao se interessar pelas regularidades e descontinuidades discursivas, Foucault recusa a figura individual de um autor como princípio de formulação dos enunciados, como unidade e origem dos discursos, procurando, ao invés disso, tratar os discursos como práticas que dispersam o sujeito (Foucault, 2012a; Foucault, 2012b). A análise foucaultiana de discurso não busca recobrir um não dito, aquilo que teria sido apagado pelo esquecimento, as manifestações inconscientes nem a intencionalidade 
de um sujeito falante, mas se interessa pelo modo como certos enunciados adquirem estatuto de discursos verdadeiros, passando, portanto, a exercer efeitos de poder.

Ao conceber o discurso como um conjunto de acontecimentos descontínuos que sempre se efetivam no âmbito da materialidade, Foucault (2012b, p. 55) considera o descontínuo como "cesuras que rompem o instante e dispersam o sujeito em uma pluralidade de posições e de fundações possíveis". Desse modo, a análise que fazemos dos materiais de pesquisa adota uma perspectiva que não concebe os proponentes dos documentos como portadores desses discursos - no sentido de que não emanam de um indivíduo ou autor que seria sua fonte - mas como sendo aqueles que os enunciam a partir de determinadas condições e ocupando certas posições-sujeito - nesse caso, deputados na Câmara do Legislativo Federal Brasileiro - tendo em vista que a autoria, conforme Foucault (2012a; 2012b) refere-se a uma função e não a uma individualidade ou identidade de certos sujeitos.

Ao caracterizarmos nossa pesquisa como arqueológica, interrogamos os documentos analisados com as seguintes questões: que regimes de verdade eles produzem? E quais efeitos de verdade são construídos em torno dos jovens autores de atos infracionais?

\section{Resultados e discussão}

\section{Tecnologias de informação e comunicação de massa e maturidade dos sujeitos}

Ao tomarmos as teorizações de Michel Foucault como principal referencial para a construção do problema de pesquisa e do percurso metodológico, ressaltamos que nesta perspectiva buscamos problematizar enunciados e discursos como práticas sociais e históricas que mobilizam, engendram e capturam sujeitos. Foucault (2012b) concebe o discurso como um conjunto de enunciados que advém de uma mesma formação e exerce efeitos de poder a partir da linguagem, das instituições, tecnologias e práticas sociais. Os enunciados, por sua vez, são proposições ou frases consideradas a partir das condições de existência pelas quais atravessam as formações discursivas de uma sociedade.

$\mathrm{Na}$ análise dos nossos materiais de pesquisa, a referência às tecnologias de informação e aos meios de comunicação de massa, como fatores que trouxeram mais acesso à informação, chamou a nossa atenção, pois possibilita que se afirme nessas PECs que não se pode conceber os jovens como se concebia na época do Código Penal de 1940. A PEC 171/1993, à qual as demais são apensadas, destaca que o acesso à informação é infinitamente superior ao acesso que os jovens tinham em 1940, década em que se formulou o Código Penal. Já a PEC 260/2000, por exemplo, afirma que "a quantidade de informação que recebem, por todos os meios de comunicação disponíveis, faz crer no amadurecimento mais precoce" (PEC 260/2000, p. 33615 ). 0 quadro a seguir mostra um panorama geral dessas produções discursivas nos documentos em questão. 


\section{Quadro I. Tecnologias de informação e meios de comunicação de massa nas PECs}

\begin{tabular}{|c|c|}
\hline Número da PEC & Excertos dos materiais de análise \\
\hline PEC I7I/1993 & $\begin{array}{l}\text { O acesso destes [jovens] à informação - nem sempre de boa qualidade - é } \\
\text { infinitamente superior àqueles de } 1940(\ldots)\end{array}$ \\
\hline PEC 9I/I995 & $\begin{array}{l}\text { Meios de comunicação e desenvolvimento tecnológico têm proporcionado uma visão } \\
\text { precoce da realidade; }\end{array}$ \\
\hline PEC 386/1996 & $\begin{array}{l}\text { A juventude alcança ampla maturidade física e psicológica (...) seja por efeito da ampla } \\
\text { evolução da sociedade, da extraordinária eficiência dos meios de comunicação (...) }\end{array}$ \\
\hline PEC 426/I 996 & $\begin{array}{l}\text { Os jovens já estão suficientemente amadurecidos, devido aos meios de comunicação } \\
\text { que os informam de todas as coisas; }\end{array}$ \\
\hline PEC 531// 997 & $\begin{array}{l}\text { O jovem contemporâneo de dezesseis anos já é plenamente consciente dos atos que } \\
\text { pratica, dispondo de informações e conhecimentos inimagináveis. }\end{array}$ \\
\hline PEC 68/1999 & $\begin{array}{l}\text { Não se há que falar que são imaturos, que não têm desenvolvimento mental } \\
\text { completo, pois a gama de informações que recebem a cada minuto torna-os } \\
\text { cônscios de seus atos (...) }\end{array}$ \\
\hline PEC I50/1999 & $\begin{array}{l}\text { A quantidade de informações que recebem, por todos os meios de comunicação } \\
\text { disponíveis, faz com que eles amadureçam e entendam o caráter extremamente } \\
\text { pernicioso de sua conduta (...) }\end{array}$ \\
\hline PEC 167/1999 & $\begin{array}{l}\text { Dado o inigualável volume de informações que o cidadão recebe, a maturidade do } \\
\text { indivíduo é alcançada muito mais rapidamente do que antigamente. }\end{array}$ \\
\hline PEC 169/1999 & $\begin{array}{l}\text { O jovem de hoje, com a velocidade e a acessibilidade das informações que o mundo } \\
\text { disponibiliza, tem plena e absoluta capacidade de discernimento da prática do crime } \\
\text { (...) }\end{array}$ \\
\hline PEC 260/2000 & $\begin{array}{l}\text { A quantidade de informações que recebem, por todos os meios de comunicação } \\
\text { disponíveis, faz crer no amadurecimento mais precoce (...) }\end{array}$ \\
\hline PEC I79/2003 & $\begin{array}{l}\text { Ora, o mundo hoje não é o mesmo mundo do Código Penal de } 1940 \text { quando } \\
\text { realmente o jovem poderia ainda não ter consciência de seus atos. Hoje a } \\
\text { informação chega em segundos a qualquer lugar do planeta (...) }\end{array}$ \\
\hline PEC 272/2004 & $\begin{array}{l}\text { Como naquela época os meios de comunicações e de informação eram bastante } \\
\text { precários no país, o menor de } 18 \text { anos era passível de ser apenado, hoje não se justifica } \\
\text { a limitação que os defensores da imputabilidade penal aos } 18 \text { anos querem sustentar. }\end{array}$ \\
\hline PEC 345/2004 & $\begin{array}{l}\text { Atualmente, os jovens têm maior acesso à informação e, por conseguinte, maior } \\
\text { capacidade de discernimento (...) }\end{array}$ \\
\hline PEC 489/2005 & $\begin{array}{l}\text { A proteção ao menor vem de uma época em que as crianças e adolescentes } \\
\text { não eram expostas a um volume intenso de informação (...) [grifo nosso]. }\end{array}$ \\
\hline PEC 87/2007 & $\begin{array}{l}\text { A sociedade vive hoje novos tempos, transformada pelo poder da informação e da } \\
\text { comunicação, com evidentes impactos no processo de formação da personalidade } \\
\text { do homem. }\end{array}$ \\
\hline PEC 228/20I 2 & $\begin{array}{l}\text { Hoje, com o aumento populacional e o consequente melhoramento dos meios de } \\
\text { comunicação, além do maior acesso à educação, não podemos mais considerar os } \\
\text { adolescentes de hoje como ingênuos ou tolos. }\end{array}$ \\
\hline PEC 279/2013 & $\begin{array}{l}\text { (...) diante dos avanços tecnológicos e sociais, que favorecem a globalização e } \\
\text { representam estímulos cada vez mais precoces ao desenvolvimento das pessoas, o } \\
\text { jovem dos dias de hoje é muito diferente daquele que vivia em 1940, quando foi } \\
\text { estabelecida a maioridade penal a partir dos } 18 \text { anos, pelo Código Penal. }\end{array}$ \\
\hline PEC 302/2013 & $\begin{array}{l}\text { (...) os jovens, através da internet e da difusão dos meios de comunicação de massa, } \\
\text { possuem um acesso amplo a toda sorte de informações, o que contribui para o seu } \\
\text { amadurecimento mais precoce. }\end{array}$ \\
\hline
\end{tabular}

Fonte: Elaborado pelas autoras (2015). 
Conforme mostra o Quadro 1, as PECs expressam uma concepção de que a quantidade de informações e o acesso aos meios de comunicação constituem-se como fatores que diferenciam a juventude atual de gerações anteriores. As PECs vão associando, então, o acesso à informação e aos meios de comunicação de massa com o discernimento, a consciência e a maturidade dos sujeitos.

Dessa maneira, uma questão primordial é a relação dos sujeitos com novas tecnologias e meios de comunicação de massa, que os levaria a "saltarem" para um estágio de amadurecimento próprio da idade adulta. As propostas analisadas produzem, portanto, uma objetivação da juventude atrelada à informação. Nesse caso, o sujeito não é tomado, por exemplo, a partir de concepções que vinculam a adolescência a um período evolutivo da vida, que teria como características intrínsecas o conflito, a rebeldia e a transição para a idade adulta (Dell'Aglio, Santos, \& Borges, 2004; Jacobina \& Costa, 2007), pois o critério da faixa etária não é tomado, em si, como relevante nessas propostas. Romper com noções essencialistas e conceber os sujeitos para além de determinadas características atribuídas a eles a partir de sua faixa etária é importante, mas a forma como essa ruptura é enunciada nos discursos desses documentos constitui-se como uma estratégia para a qual precisamos estar atentos, pois, é justamente ao abdicar desse critério da faixa etária e atrelar a maturidade juvenil a um maior volume de informação e ao contato com novas tecnologias, que os legisladores afirmarão a necessidade de aumentar o rigor punitivo sobre os jovens, produzindo um jogo de verdades em torno da consciência e do discernimento como critérios que deveriam balizar a imputabilidade penal.

O que se enuncia é a produção de um sujeito consciente no sentido de que, ao associar o acesso à informação a uma mudança de mentalidade, é possível afirmar que esses jovens possuem informações suficientes para saber o que fazem e que, portanto, devem responder judicialmente como adultos diante de seus atos. A quantidade de informações, a velocidade e o domínio das tecnologias Ihes proporcionariam uma maturidade psíquica antecipada. Assim, o domínio das tecnologias é também tomado como sinônimo de um domínio de si.

Essa concepção de sujeito remete ao projeto da modernidade, cuja racionalidade instituiu, sobretudo a partir da filosofia cartesiana, a noção de indivíduo como ser dotado de autonomia, consciência e razão. Segundo Mancebo (2002), um dos universais modernos, sobretudo a partir da filosofia de Descartes, é a ideia de que o homem é o centro e o fundamento do mundo. Além disso, a noção de self, que é criada com o desenvolvimento e a consolidação da psicologia como disciplina científica, no século $X X$, possibilita a compreensão da subjetividade em termos de identidade, de autonomia, liberdade e realização pessoal (Rose, 2008), configurando um vasto campo de intervenções nos quais a Psicologia adquire cada vez mais capilaridade e legitimidade.

Hillesheim e Guareschi (2007) afirmam que a Psicologia do Desenvolvimento surge comprometida com os valores da modernidade. As autoras assinalam a relação existente entre os valores de razão, emancipação e progresso, disseminados pelo projeto 
da modernidade, e muitos saberes construídos por algumas teorias do desenvolvimento, que postulam a existência de estágios em que haveria determinados graus progressivos de maturidade dos sujeitos. É essa concepção de que haveria etapas adequadas ao desenvolvimento "normal", de acordo com idades específicas, que permeia as PECs quando se afirma que os sujeitos passaram a amadurecer de modo precoce.

De acordo com Rizzini (2011), a noção de discernimento foi sustentada na prática jurídica durante séculos, possibilitando a aplicação de penas a menores de idade de acordo com o seu grau de consciência diante dos atos praticados. Posteriormente, essa noção de discernimento passou a ser questionada no meio jurídico. A autora afirma que "nas duas primeiras décadas do século XX, período de formulação de uma legislação específica para os menores, a noção de discernimento foi abertamente ridicularizada e veio a ser erradicada com a promulgação do Código de Menores de 1927" (Rizzini, 2011, p. 85). Mesmo tendo sido abandonada após o Código de Menores, as PECs analisadas retomam essa noção de discernimento como critério para decidir sobre a imputabilidade de jovens. No entanto, esse retorno vem sob nova roupagem, na medida em que há uma articulação com a expansão dos meios de comunicação e do acesso à informação.

Ao articularem os meios de comunicação com um amadurecimento supostamente precoce, pressupõe-se um grau de maturidade ideal a ser atingido a partir de um determinado período da vida. Ademais, produz-se também uma homogeneização da juventude, como se o acesso à informação se constituísse a partir de um padrão para todos os sujeitos. As relações estabelecidas com essas tecnologias de comunicação e informação, bem como os processos de significação, dessas informações são tomadas sempre no sentido de uma maturidade precoce, sem que se coloquem em discussão processos de singularização dos sujeitos.

A noção de juventude como incapaz de decidir e avaliar seus atos é comprimida pela disponibilização de informação e suposta capacidade de síntese dessa informação, que deveria constituir o adulto responsável, e, portanto, penalizável por seus atos. Pode-se pensar, assim, que não se trata tanto de uma mudança na concepção sobre os jovens, mas de como eles podem atingir a maturidade cada vez mais cedo, pela perda de sua "ingenuidade" ou "tolice", obliterando as próprias possibilidades de mudança desse sujeito, já que a maturidade adulta é tida como o ponto final e culminante de um processo de constituição de uma personalidade irreversível e racional. Nesse sentido, os discursos produzidos relacionam-se com a juventude de um modo fatalista, pois diante de jovens "delinquentes" e tidos como precoces, as possibilidades de intervenção restringem-se ao aprisionamento no sistema penitenciário para adultos. Ao tratá-los como sujeitos "prontos e acabados" devido ao acesso à informação, os legisladores propõem o rebaixamento da idade penal como forma de punir mais "adequadamente" os sujeitos, ou seja, reivindicando que eles sejam imputáveis diante do Código Penal.

Além disso, também é importante notar que essas propostas abdicam de uma concepção de desenvolvimento atrelada a fatores biológicos, a uma evolução da 
idade e amadurecimento corporal dos sujeitos. Na medida em que a noção de desenvolvimento passa a ser associada às tecnologias de comunicação, consideram-se alguns efeitos do contexto cultural sobre os sujeitos, já que quando falam de mudanças provocadas pelas tecnologias, referem-se aos processos que se dão na esfera sociocultural. Paradoxalmente, é justamente a partir de um reconhecimento da construção social dos sujeitos que se propõe mais rigor punitivo diante da responsabilização individual diante de um ato infracional. Ao atentarmos para o modo como esses discursos vão associando informação e maturidade, não se trata de afirmarmos que os jovens não teriam maturidade ou responsabilidade, mas sim de evidenciar esse jogo entre o acesso à informação e um maior rigor punitivo para esses sujeitos. Dito em outros termos, trata-se de estranhar como os meios de comunicação são naturalizados como sinônimo de uma antecipação da maturidade e pensar os efeitos dessa produção de verdades. Um desses desdobramentos, que passaremos a abordar a seguir, é a substituição do critério cronológico por um outro critério tido como "psicossocial" ou "subjetivo-psicológico" proposta nas PECs a partir dos regimes de verdade que articulam maturidade com meios de comunicação e tecnologias de informação.

\section{Do critério cronológico ao discernimento e à consciência dos jovens}

A concepção de sujeito a partir do discernimento, da consciência e de uma maturidade psíquica atravessa as alterações propostas ao artigo 228 da Constituição Federal no tocante à imputabilidade. Primeiramente, as PECs propõem a redução da idade penal com base no critério cronológico, isto é, propondo fixar a idade de imputabilidade penal a partir dos 16, 14, 12 anos de idade etc. No entanto, a partir da década de 2000, propõe-se uma substituição desse critério por um critério "psicossocial", buscando englobar características que remetem ao discernimento diante de atos praticados, consciência e amadurecimento psíquico independentemente da idade em que se praticou determinado ato infracional. Esses elementos, ao serem colocados em questão com mais força, promovem as seguintes proposições:

Prévia avaliação psicológica, podendo o juiz concluir pela sua imputabilidade, se julgar que o seu grau de maturidade justifica a aplicação da pena (PEC 489/2005, p. 1).

Capacidade de entender o caráter delituoso do fato e de autodeterminar-se conforme esse entendimento através de laudo médico e psicológico (PEC 73/2007, p. 1).

(...) nos crimes hediondos ou a estes equiparados, o menor, entre dezesseis e dezoito anos, poderá ser emancipado para responder criminalmente de acordo com a legislação penal, após avaliação por equipe multidisciplinar, integrada pelo Ministério Público e designada pelo Órgão judiciário; que avaliará sua maturidade emocional, mental e intelectual e determinará a sua consciência, ao tempo da ação, do caráter ilícito do ato praticado e as condições de determinar-se de acordo com esse entendimento (PEC 273/2013, não paginado). 
Primeiramente, os proponentes dessas PECs apontam que há discernimento e maturidade suficientes para que jovens com idade abaixo de 18 anos entendam a sua conduta quando praticam atos infracionais e, posteriormente, em grande parte das PECs, eles propõem que se avalie se esses jovens possuem um grau de maturidade e entendimento adequado de seus atos, a fim de sejam "devidamente" punidos. A partir disso, os saberes PSI são convocados a atestar as características psicossociais e a conduta dos sujeitos que praticaram algum ato infracional.

Os estudos de Foucault $(2003 ; 2010)$ sobre a constituição da penalidade moderna mostram como, sobretudo, a partir do século XIX, a investigação de certos atributos psicológicos passam a ser decisivos na determinação jurídica das punições. A instituição judiciária, aliada a uma série de saberes, busca desenvolver técnicas corretivas dos indivíduos. Para isso, volta-se às circunstâncias atenuantes: a aplicação da lei passa a ser modificada em função do indivíduo em julgamento. A Psicologia é "intimada" à realização de exames, testes e avaliações que qualificam e classificam os sujeitos, atribuindo-lhes estreita relação entre o que fazem, o que podem fazer e aquilo que são.

A convocação da Psicologia para responder a essas demandas em torno da redução da idade penal adquire contornos paradoxais, pois, se, por um lado, os saberes psicológicos produzem uma concepção de sujeito livre, dotado de consciência, de um interior psicológico e discernimento sobre si e seus atos, de outro lado, ela tem-se posicionado, institucionalmente, por meio do Conselho Federal da profissão, contrária a essa redução. Temos, desse modo, uma luta de forças também no interior da própria área de conhecimento, pois é a partir da multiplicidade de teorias e instrumentos elaborados pela Psicologia que se demandam e se sustentam avaliações psicológicas nesse contexto da imputabilidade penal, mas, por outro lado, também se produzem enfrentamentos e recusas a esse tipo de avaliação na própria área. As divergências epistemológicas, teóricas e ético-políticas na Psicologia permeiam essa produção de embates e confrontos discursivos e políticos.

Considerando-se o modo como os saberes da Psicologia são chamados a responder à demanda por avaliações sobre jovens, a fim de subsidiar decisões judiciais acerca da aplicação de penas, os posicionamentos e publicações do CFP, que mencionamos na introdução desse artigo, certamente configuram-se como formas de recusa à "colaboração" nessas avaliações. No entanto, mesmo após o ano de 2007, as propostas apresentadas na Câmara de Deputados continuam defendendo a realização de avaliações por equipes multiprofissionais, em que deverão constar psicólogos, a fim de embasar decisões judiciais. A demanda, de modo insistente, de diversas dessas PECs pela participação de psicólogos em avaliações que possibilitarão decidir o tipo mais "adequado" de punição para certos jovens coloca em discussão o modo como as alianças entre a Psicologia e o Judiciário são marcadas por tensionamentos.

Entendemos que essa convocação da Psicologia, dentre outras profissões das Ciências Humanas, para elaboração de avaliações sobre o psiquismo dos jovens, tem alguns efeitos importantes. Primeiramente, evidencia que, apesar de ainda não terem sido 
aprovadas, as propostas favoráveis à redução da idade penal possibilitam a inscrição de práticas concretas na sociedade. Nesse sentido, apontamos que elas têm uma positividade em fazer falar, em acionar discursos, sujeitos, modos de governo e intervenção sobre a juventude. Além disso, a mudança proposta para os critérios de definição da imputabilidade penal tem como um de seus efeitos a produção de confrontos que mobilizam a Psicologia a se posicionar e a discutir a atuação demandada em certos contextos jurídicos. Desse modo, as implicações de uma possível efetivação da redução da idade penal para o campo da Psicologia são relevantes, pois convocam-na a atuar nesse contexto, apesar de a categoria profissional, por meio do Conselho Federal de Psicologia, vir se manifestando contrariamente a essa redução. Assim, os embates em que ela se insere explicitam confrontos políticos e éticos.

Pode-se afirmar, então, que as propostas de redução da idade penal no Brasil relacionam a expansão das tecnologias de informação e dos meios de comunicação de massa de modo a produzir efeitos de subjetivação-objetivação acerca de uma suposta maturidade, que se desenvolveria de modo precoce e possibilitaria. Dessa maneira, torna os sujeitos com idade inferior a 18 anos imputáveis penalmente.

Ao articularem maturidade psíquica e discernimento com tecnologias, coloca-se também em discussão uma flexibilização dos critérios para consideração da imputabilidade penal. Ao se estabelecer como critério a avaliação de uma equipe multidisciplinar, torna-se possível que jovens de quaisquer idades sejam passíveis do cumprimento de penas no sistema prisional, de acordo com os laudos e pareceres das juntas formadas por profissionais, como médicos e psicólogos, o que amplia o escopo daqueles que podem ser penalizáveis. Desse modo, a partir de certos processos sociais, como o acesso à informação, esses discursos propõem mais individualização das formas de punição sobre os jovens, uma vez que se prevê a flexibilização penal com base em avaliações caso a caso, realizadas por equipes multidisciplinares - compostas por psicólogos, assistentes sociais, psiquiatras etc. - que deverão aferir o grau de maturidade, consciência e discernimento de jovens diante da prática de atos infracionais, buscando atestar se podem ser considerados imputáveis ou não. Isso gera embates políticos e éticos sobre a atuação da Psicologia.

Não nos isentamos de um posicionamento político quanto à discussão empreendida aqui. Basta, nesse sentido, apontar que direcionamos nosso olhar para o modo como a Psicologia é tensionada nessas propostas por nos inserirmos nessa área de conhecimento e partilharmos das discussões e do posicionamento contrário à redução da idade penal adotado por diversas entidades da profissão, o que, evidentemente, não implica dizer que seja um posicionamento pacífico nem unânime na área, pois é justamente a multiplicidade de perspectivas na Psicologia que a situa em embates e conflitos quanto à sua atuação. 


\section{Referências}

Alves, C., Pedroza, R., Pinho, A., Presotti, L., \& Silva F. (2009). Adolescência e maioridade penal: reflexões a partir da Psicologia e do Direito. Psicologia Política, 9(17), 67-83. Disponível em: http://pepsic.bvsalud.org/pdf/rpp/v9n17/v9n17a05.pdf.

Bocco, F. (2006). Cartografias da infração juvenil. Dissertação de Mestrado, Programa de Pós-Graduação em Psicologia, Universidade Federal Fluminense (UFF), Niterói, RJ, Brasil.

Cãmara dos Deputados (2000). Proposta de Emenda à Constituição 260/2000. Disponível em: http://imagem.camara.gov.br/imagem/d/pdf/dcd22jun2000. pdf\#page $=71$.

Conselho Federal de Psicologia (CFP) (2007). Campanha contra redução da maioridade penal: entidades resgatam pensamento do sociólogo Betinho. Disponível em: http://www.pol.org.br/pol/cms/pol/noticias/noticia_070720_821.html.

Conselho Federal de Psicologia (CFP) (2013a). Redução da maioridade penal. Disponível em: http://site.cfp.org.br/reducao-da-maioridade-penal/.

Conselho Federal de Psicologia (CFP) (2013b). Redução da idade penal: sócio educação não se faz com prisão. Brasília, DF: Conselho Federal de Psicologia.

Coimbra, C., Bocco, F., \& Nascimento, M. L. (2005). Subvertendo o conceito de adolescência. Arquivos Brasileiros de Psicologia, 57(1), 2-11.

Cunha, P. I., Ropelato, R., \& Alves M. P. (2006). A redução da maioridade penal: questões teóricas e empíricas. Psicologia: Ciência e Profissão, 26(4), 646-659. DOI: 10.1590/S1414-98932006000400011.

Dell'Aglio, D. D., Santos, S. S., \& Borges, J. L. (2004). Infração juvenil feminina: uma trajetória de abandonos. Interação em Psicologia, 8(2), 191-198. DOI: 10.5380/psi. v8i2.3255.

Foucault, M. (2003). A verdade e as formas jurídicas. 3a ed. Rio de Janeiro: Nau Editora.

Foucault, M. (2010). Vigiar e punir: nascimento da prisão. 38a ed. Petrópolis: Vozes.

Foucault, M. (2012a). A arqueologia do saber. 8a ed. Rio de Janeiro: Forense Universitária.

Foucault, M. (2012). A ordem do discurso. 22a ed. São Paulo: Edições Loyola.

Hillesheim, B., \& Guareschi. N. M. F. (2007). De que infância nos fala a Psicologia do Desenvolvimento? In N. M. F. Guareschi \& S. M. Hüning (Orgs.). Implicações da Psicologia no Contemporâneo (pp. 83-134). Porto Alegre: EDIPUCRS. 
Jacobina, O. M. P., \& Costa, L. F. (2007). "Para não ser bandido": trabalho e adolescentes em conflito com a lei. Cadernos de Psicologia Social do Trabalho, 10(2), 95-110. DOI: 10.11606/issn.1981-0490.v10i2p95-110.

Mancebo, D. (2002). Modernidade e produção de subjetividades: breve percurso histórico. Psicologia: Ciência e Profissão, 22(1), 100-111. DOI: 10.1590/S141498932002000100011.

Novaes, R. C. R., Cara, D. T., Silva, D. M., \& Papa, F. C. (Orgs.). (2006). Política Nacional de Juventude: diretrizes e perspectivas. São Paulo: Conselho Nacional de Juventude/Fundação Friedrich Ebert.

Rizzini, I. (2011). O século perdido: raízes históricas das políticas públicas para infância no Brasil. 3a ed. São Paulo: Cortez.

Rose, N. (2008). Psicologia como uma ciência social. Psicologia e Sociedade, 20(2), 155-164. DOI: 10.1590/S0102-71822008000200002.

Santana, J. E. (1993). Revisão Constitucional - reforma e emendas. Belo Horizonte: Del Rey.

Submissão: 22.1.2016

Aceitação: 14.9.2016 